\title{
REMOVAL OF NATURAL ORGANIC MATTER FROM GROUNDWATER USING FENTON'S PROCESS
}

\author{
B. KALAJDŽİ́ ${ }^{1}$ \\ M. HABUDA-STANIĆ ${ }^{1, *}$ \\ Ž. ROMIĆ ${ }^{2}$ \\ M. KULEŠ ${ }^{1}$
}

\author{
${ }^{1}$ Department of Water Technology and Ecology \\ Faculty of Food Technology \\ J.J. Strossmayer, Osijek, Croatia Greece \\ 2 "Vodovod-Osijek" d.d., Osijek, Croatia
}

Received: $18 / 03 / 10$

Accepted: 25/10/12 *to whom all correspondence should be addressed: e-mail: mirna.habuda-stanic@ptfos.hr

\begin{abstract}
Groundwater in the area of eastern Croatia contains increased concentrations of organic compounds, primarily natural organic matter (NOM). Organic compounds in water become a problem in drinking water treatment, especially during water disinfection with chlorine, when harmful disinfection by-products like trihalomethanes appear. Therefore, the removal of disinfection byproducts (DBP) precursors gains high importance.

This paper deals with the efficiency of NOM removal from groundwater by the Fenton's process and its influence on trihalomethane formation potential (THMFP). In this research performance of Fenton process at conditions close to conditions of natural groundwater was investigated. $\mathrm{pH}$ value was not decreased under 4.5 and attempt was done to perform Fenton's process at natural iron concentration in groundwater of town Osijek area. Once optimized, process achieved about $50 \%$ removal of TOC $\left(2.5 \mathrm{mM} \mathrm{H}_{2} \mathrm{O}_{2} ; 0.1 \mathrm{mM} \mathrm{Fe}{ }^{2+} ; \mathrm{pH} 4.5\right)$ and decrease of THMFP $\left(\mathrm{A}_{254} / \mathrm{A}_{203}\right)$ for about $70 \%\left(5 \mathrm{mM} \mathrm{H}_{2} \mathrm{O}_{2} ; 0.1 \mathrm{mM} \mathrm{Fe}{ }^{2+} ; \mathrm{pH} 4.5\right)$. Under adequate conditions Fenton process could be successfully used for the removal of organic contaminants from groundwater.
\end{abstract}

KEYWORDS: Fenton's process, natural organic matter, THMFP, groundwater.

\section{INTRODUCTION}

Groundwater contains large quantities of dissolved compounds as a result of interactions of hydrological cycles with the biosphere and geosphere. The consequence is occurrence of many inorganic and organic compounds in water, which can be harmful for human health. Groundwater of eastern Croatia, especially in the area of the town Osijek, is characterized by high water hardness and increased concentrations of inorganic contaminants like iron, manganese, ammonium and arsenic, as well as increased concentrations of organic compounds, primarily natural organic matter (NOM) (Habuda-Stanić et al., 2007). These concentrations exceed maximum permissible concentration (MPC) for the drinking water regulated by the Croatian laws (Narodne novine, 2004) and recommendations of the World Health Organization (WHO) (WHO, 1993). The above mentioned water is not suitable for drinking without the proper treatment. The current water treatment is the conventional treatment based on chemical coagulation/ flocculation process. Concentrations of the most contaminants can be decreased by this conventional method to the level permitted by the law. Since the concentrations of the contaminants are heightened, large amounts of chemicals are used during the water treatment, which results in low quality of produced water. Arsenic and organic matter concentrations after treatment still remain around or above MPC.

NOM is a complex mixture of organic materials like humic acids, hydrophilic acids, proteins, lipids, carbohydrates and amino acids. NOM changes organoleptic characteristics of water like taste, smell and color. Harmful effects of NOM are most intensively expressed during water chlorination process when NOM is used as precursor in synthesis of harmful disinfection by-products (DBP) which show high mutagen and carcinogenic effects (Cohn et al., 1999, Singer, 1999). 
There has been a great interest in the use of advanced oxidation processes (AOPs) for the treatment of water contaminants. These processes are characterized by their ability to form the strong oxidizing species, the hydroxyl radicals in water. The hydroxyl radicals have been reported to oxidize a range of organic compounds. In this paper we report the treatment of NOM rich water with Fenton's reagent. Fenton's reagent is a catalytic oxidative mixture that contains iron ions and hydrogen peroxide. In this process hydroxyl radicals are produced during the decomposition of hydrogen peroxide in the presence of ferrous salts (Walling, 1975).

$$
\begin{aligned}
& \mathrm{H}_{2} \mathrm{O}_{2}+\mathrm{Fe}^{2+} \rightarrow \mathrm{HO} \cdot+\mathrm{OH}^{-}+\mathrm{Fe}^{3+} \\
& \cdot \mathrm{OH}+\mathrm{RH} \rightarrow \text { Oxidation products }
\end{aligned}
$$

The generated $\mathrm{OH}$ radicals have a strong oxidizing potential and they are capable of oxidizing wide range of compounds.

Fenton's process has the potential to treat water rich in NOM (ljpelaar et al., 2002a, Murray and Parsons, 2004a; 2004b, Stasinakis, 2008). The performance of the process is significantly better than coagulation with iron salts (Murray and Parsons, 2004a; 2004b). The key parameters, which determine the removal efficiency, are $\mathrm{pH}$ and the $\mathrm{Fe}^{2+}$ dose (Murray and Parsons, 2004a). Process performance is also dependent on reaction time, peroxide dose and organic strength (Murray and Parsons, 2004a, ljpelaar et al., 2002b, Stasinakis, 2008).

Besides NOM removal from water, Fenton's process can be successfully used for elimination of many different contaminants from natural water and wastewater. Good removal of DBPs like THMs (Tang and Tassos, 1997) was achieved, as well as removal of precursor species which can be problematic with respect to THM formation potential (THMFP) (Murray and Parsons, 2004b, Kleiser and Frimmel, 2000). Fenton's process is a promising method for pesticide control in groundwater and surface water (ljpelaar et al., 2002a, ljpelaar et al., 2002b). Phenols can be completely removed by the Fenton's process (Kavitha and Palanivelu, 2004). Various applications of Fenton's reagent have been developed for wastewater contaminants removal. Recent review paper (Stasinakis, 2008) points benefits of Fenton's reaction variation, such as photo-Fenton process $\left(\mathrm{H}_{2} \mathrm{O}_{2} / \mathrm{Fe}^{2+} / \mathrm{UV}\right)$ which can significantly reduce the operational cost of the wastewaters treatment. Laboratory tests confirmed effective application of photo-Fenton treatment during wastewater colour reduction, when up to $90 \%$ of colour reduction was achieved (Ferreira et al., 2008). Enhancement in landfill leachate biodegradability by conventional biological wastewater treatment was also accomplished during laboratory testing using Fenton's reagent as pre-treatment (Petruzzeli et al., 2007). Other researches of Fenton's process application for removal of various compounds from wastewater also reported good results and increasing of wastewater treatment efficiency (Kavitha and Palanivelu, 2004, Kang et al., 2002, Korshin et al., 1997). A few researches have been done to clarify the use of Fenton's process for treatment of natural water for drinking water purpose and that investigations were done using optimal conditions for Fenton's reaction (ljpelaar et al., 2002a, Murray and Parsons, 2004b). Despite of all above mentioned, Stasinakis in his review paper emphasized that future challenges for AOPs, as well as Fenton's reaction, could be, among the other, commercialization of processes, since most of these good results are obtained during testing in laboratory controlled conditions (Stasinakis, 2008).

The purpose of this study was to investigate the possibility of application of Fenton's process for the removal of NOM from groundwater in the conditions close to real. The focus is to study the implementation of Fenton's process in drinking water treatment process and to find adequate alternative for conventional process of drinking water treatment in the town of Osijek.

\section{METHODOLOGY}

Raw groundwater, which contains high concentration of NOM, was treated with the Fenton's process. The purpose of this research was to determine optimal conditions for oxidation and removal of NOM from groundwater by varying process parameters: $\mathrm{pH}, \mathrm{H}_{2} \mathrm{O}_{2}$ and $\mathrm{Fe}^{2+}$ dose. When the values of the process parameters were chosen, the possibility of application in the real conditions was taken into account since the main purposes of this work was to find adequate alternative for conventional process of drinking water treatment in the town of Osijek. pH value was varied from 4.5 till 7.5 . It is well known that the optimum $\mathrm{pH}$ of Fenton's reaction is $2.5-3.5$ for the removal of organic substances (Walling, 1975), but in this research performance of Fenton's process at $\mathrm{pH}$ values close to $\mathrm{pH}$ of natural water was investigated. Fenton process tests were 
performed using standard jar test apparatus (Biblock Scientific Floculateur 10405). Experiments were performed using raw water obtained from water-wells that provide water for waterworks of town Osijek, eastern Croatia. $1 \mathrm{~L}$ samples were used for jar tests. The Fenton's process was conducted at $\mathrm{Fe}^{2+}$ concentration that corresponds to natural concentration of iron in groundwater $(0,02 \mathrm{mM})$ and at $\mathrm{Fe}^{2+}$ concentration of $0.1 \mathrm{mM}$. $\mathrm{pH}$ adjustment was carried out after addition of the $\mathrm{Fe}^{2+}$ using $0.1 \mathrm{M} \mathrm{HCl}$. After $\mathrm{pH}$ adjustment $\mathrm{H}_{2} \mathrm{O}_{2}$ was added. $\mathrm{H}_{2} \mathrm{O}_{2}$ concentration was $1,2.5$ and 5 $\mathrm{mM}$. In the current conventional water treatment process in waterworks of the town of Osijek, for water to pass through treatment plant, from aeration to filtration, 30 minutes is needed and this time period was used in experimental work. The process lasted for 30 minutes and was conducted with stirring at $120 \mathrm{rpm}$. Certain efforts were made to increase process effectiveness and flocculant aid polyelectrolyte and powered activated carbon was added. The effect of the type of additional materials on removal of oxidized components from water was monitored. In order to make removal of oxidized components by filtration easier, a flocculant aid polyelectrolyte was added to enhance formation of larger floccules that would be retained on a filter. Another way was to add powdered activated carbon, which adsorbed organic components on their surface and made a removal of the adsorbed components by filtration easier. Additional materials were added in concentration close to that applicable in practice: $0.6 \mathrm{mg} \mathrm{L}^{-1}$ of polyelectrolyte (Accepta 4211) and $25 \mathrm{mg} \mathrm{L}^{-1}$ of activated carbon (Norit SA Super). After additional stirring for $5 \mathrm{~min}$, samples were left to settle and were filtered after that. $\mathrm{H}_{2} \mathrm{O}_{2}$ was completely decomposed when $\mathrm{pH}$ value was set back to neutral required for drinking water and $\mathrm{H}_{2} \mathrm{O}_{2}$ concentration after reaction was not measured furthermore.

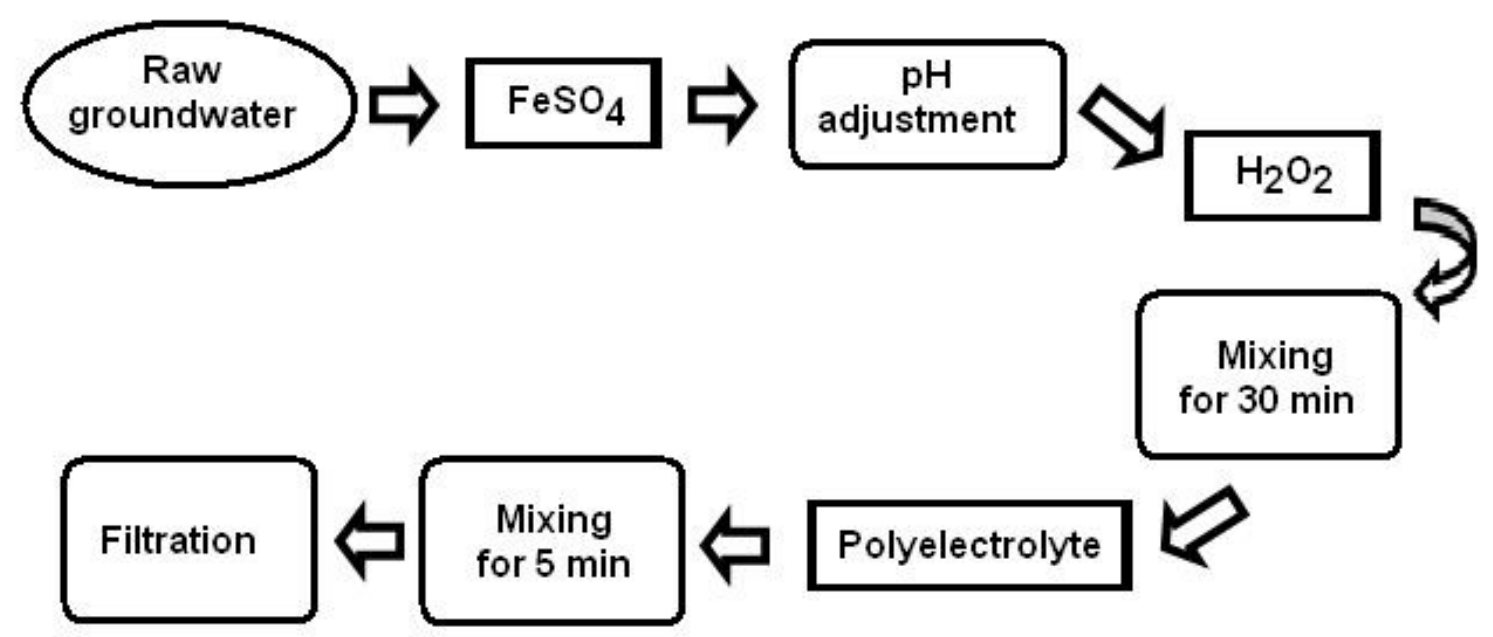

Figure 1. Steps of Fenton's process

To assure the accurancy, reliability and reproducibility of obtained results, all batch tests were performend in triplicate and mean values of obtained results only are reported. Among each replica of repeated test, the variance in reported results was around $5 \%$.

Ferrous sulphate (Kemika, Croatia) and 30 \% p.a. hydrogen peroxide (Kemika, Croatia) were used in Fenton's process experiments. TOC ( $\left.\mathrm{mg} \mathrm{L}^{-1}\right)$ was measured using a TOC Analyzer Analytik Jena multi N/C 3000. UV absorbance at $254 \mathrm{~nm}\left(\mathrm{~A}_{254}\right)$ and $203 \mathrm{~nm}\left(\mathrm{~A}_{203}\right)\left(1 \mathrm{~cm}^{-1}\right)$ were measured using a UV/VIS Spectrometer Lambda 20 Perkin Elmer. Certain surrogate parameters have been adopted to predict trihalomethane formation potential (THMFP). THMFP was calculated as a ratio of the $A_{254}$ to $A_{203}\left(A_{254} / A_{203}\right)$, for which was found to be a good surrogate parameter that is well correlated to THMFP [15]. $\mathrm{pH}$ value was determined with a $\mathrm{pH}$ meter Seven easy (Mettler, Toledo). The chemical oxygen demand (COD-Mn) was determined by titration using Kübel-Tiemann method. Concentrations of iron were determined using Lambda 20 Perkin Elmer spectrophotometer by the standard spectrometric method (Greenberg et al., 1999). 


\section{RESULTS AND DISCUSSION NOM removal}

The Fenton's process was applied to the degradation of NOM in groundwater of Osijek area. Raw water quality is shown in Table 1. High concentrations of natural organic matter are naturally occurring in groundwater of Osijek area. Quantity and characteristics of NOM were monitored using TOC and UV-spectroscopic parameters $\left(\mathrm{A}_{254}, \mathrm{~A}_{254} / \mathrm{A}_{203}\right)$.

Table 1. Quality of raw groundwater from Osijek waterworks

\begin{tabular}{lc|c}
\hline Parameter & mean & $\begin{array}{c}\text { standard } \\
\text { deviation }\end{array}$ \\
\hline $\mathrm{pH}$ & 7.5 & 0,13 \\
$\mathrm{COD}-\mathrm{Mn}\left(\mathrm{mgO}_{2} \mathrm{~L}^{-1}\right)$ & 3.94 & 0,53 \\
$\mathrm{TOC}\left(\mathrm{mg} \mathrm{L}^{-1}\right)$ & 5.45 & 0,42 \\
$\mathrm{~A}_{254}\left(\mathrm{~m}^{-1}\right)$ & 24.24 & 2,23 \\
$\mathrm{~A}_{254} / \mathrm{A}_{203}$ & 0.4626 & 0,09 \\
$\mathrm{Fe}_{\text {tot }}\left(\mathrm{mg} \mathrm{L}^{-1}\right)$ & 1.287 & 0,41 \\
$\mathrm{Fe}^{2+}\left(\mathrm{mg} \mathrm{L}^{-1}\right)$ & 1.030 & 0,39 \\
\hline
\end{tabular}

In the paper, the efficiency of the process, with respect to TOC and THMFP, are summarized. The progress of the mineralization of NOM from groundwater was monitored by measuring the TOC. The complete mineralization of NOM was not achieved. The data collected indicate that at optimal conditions $\left(2.5 \mathrm{mM} \mathrm{H}_{2} \mathrm{O}_{2} ; 0.1 \mathrm{mM} \mathrm{Fe}{ }^{2+} ; \mathrm{pH} \mathrm{4.5)}\right.$ approximately $50 \%$ of the carbon in NOM is mineralized.

The estimation of THMFP is quite complex, thus, certain surrogate parameters have been adopted to predict THMFP. Many researchers have found TOC, $A_{254}, A_{272}, S_{V V A} A_{25}$ to be good surrogate parameters that correlate well with DBPFP, especially THMFP. To clarify the degradation characteristics of NOM as a result of Fenton process, spectroscopic data were used. Absorbance at 254 and $203 \mathrm{~nm}$ was measured. THMFP was estimated as a ratio of the $A_{254}$ to $A_{203}\left(A_{254} / A_{203}\right)$, which was found to be a good indirect parameter for estimating THMFP [14]. Better results were obtained with respect to THMFP decrease compared to TOC decrease $(70 \%$ in optimal conditions when $5 \mathrm{mM} \mathrm{H}_{2} \mathrm{O}_{2}, 0.1 \mathrm{mM} \mathrm{Fe}^{2+}$ and $\mathrm{pH} 4.5$ were used). The difference indicates that various organic intermediate products were produced during the Fenton's process and remained in the solution. The data obtained suggest that the part of starting NOM compounds could not be totally degraded to $\mathrm{CO}_{2}$ during process, but the structural characteristics of that NOM portion were changed what is visible in THMFP decrease. These results indicate the formation of persistent intermediate compounds which are difficult to be degraded in Fenton's reaction, but at the same time, unsaturated components, such as aromatic moieties in the NOM, those are the main THM precursor, may well be degraded during Fenton's process.

Since the Fenton's process is controlled by the key parameters $\mathrm{pH}$, concentration of $\mathrm{Fe}^{2+}$ and $\mathrm{H}_{2} \mathrm{O}_{2}$, the parameters effect was investigated in this study.

\section{Effect of $\mathrm{pH}$ values}

The process was performed in triplicate at the following $\mathrm{pH}$ values 4.5, 5.5, 6.5, 7.5. The efficiency of Fenton's process with respect to TOC removal is strongly affected by $\mathrm{pH}$ of the solution. Lower $\mathrm{pH}$ values enhanced NOM removal process (Figure 2), and the process efficiency was decreased when approaching natural $\mathrm{pH}$ value of a raw groundwater, which was 7.5. Although the optimum $\mathrm{pH}$ of Fenton's reaction during the removal of organic substances (Walling, 1975) is in range $2.5-3.5$, lower $\mathrm{pH}$ values than 4.5 were not included in this research. The reason is that the setting of $\mathrm{pH}$ back to neutral value is quite uneconomical. At lower $\mathrm{pH}, 50 \%$ of TOC was removed and at $\mathrm{pH} 7.5$ maximum $10 \%$ of TOC was removed. At $\mathrm{pH}$ values close to neutral process efficiency is significantly lower since $\mathrm{H}_{2} \mathrm{O}_{2}$ has low stability at higher $\mathrm{pH}$ and it is self-decomposed to oxygen and water at a great extent at neutral $\mathrm{pH}$. Soon after the start of reaction no more $\mathrm{H}_{2} \mathrm{O}_{2}$ was available. Better results were obtained regarding THMFP decrease (Figure 3). In a more favorable acid region, $70 \%$ of THMFP decrease was achieved. Even here the process efficiency was decreased with increase of $\mathrm{pH}$ value, but variations of $\mathrm{pH}$ did not as much affect decrease of THMFP as TOC. The removal of precursors in THM formation and THMFP decrease was still around $60 \%$, when higher concentrations of $\mathrm{H}_{2} \mathrm{O}_{2}$ and $\mathrm{Fe}^{2+}$ were used, even if $\mathrm{pH}$ was preserved at natural value of 7.5. 


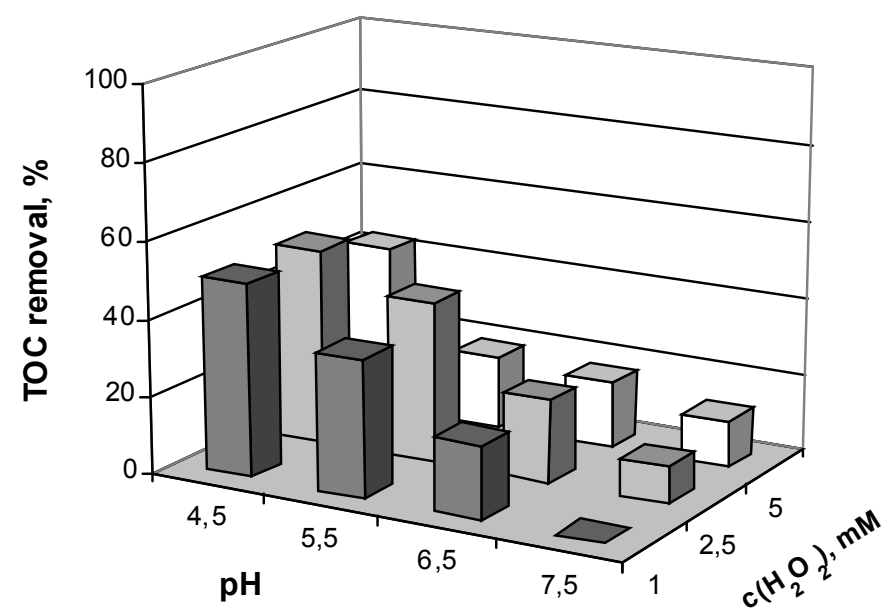

Figure 2. Effect of $\mathrm{H}_{2} \mathrm{O}_{2}$ dose on performance of Fenton's process for TOC removal (0.1 $\mathrm{mM} \mathrm{Fe}^{2+}, \mathrm{TOC}_{0} 5.45 \mathrm{mg} \mathrm{L}^{-1}, 0,6 \mathrm{mg} \mathrm{L}^{-1}$ polyelectrolyte, 30 min mixing time)

\section{Effect of $\mathrm{H}_{2} \mathrm{O}_{2}$ dose}

An important parameter of the Fenton's process is $\mathrm{H}_{2} \mathrm{O}_{2}$ dose. Since the dose of $\mathrm{H}_{2} \mathrm{O}_{2}$ determines the amount of $\mathrm{OH}$ radicals produced, TOC removal performance in the Fenton's reaction is, to a great extent, affected by the $\mathrm{H}_{2} \mathrm{O}_{2}$ dose. Figure 3 shows the effect of initial $\mathrm{H}_{2} \mathrm{O}_{2}$ concentration on the removal of TOC with the use of Fenton's process. As expected, the increase of removal efficiency for NOM with increasing the concentration of $\mathrm{H}_{2} \mathrm{O}_{2}$ added was reported what can be explained by the effect of additionally produced $\mathrm{OH}$ radicals.

The influence of hydrogen peroxide concentration is more pronounced at higher $\mathrm{pH}$ values and the concentration increase has a favorable influence on TOC removal. When $\mathrm{pH}$ value decreases, the increase of $\mathrm{H}_{2} \mathrm{O}_{2}$ dosage did not produce a significant increase in total TOC removal. An optimal concentration of $\mathrm{H}_{2} \mathrm{O}_{2}$ at lower $\mathrm{pH}$ values was $2.5 \mathrm{mM}$. An effect of $\mathrm{H}_{2} \mathrm{O}_{2}$ dose was also visible when THMFP decrease was estimated and a slight decrease of THMFP with $\mathrm{H}_{2} \mathrm{O}_{2}$ concentration increase was seen (Figure 3).

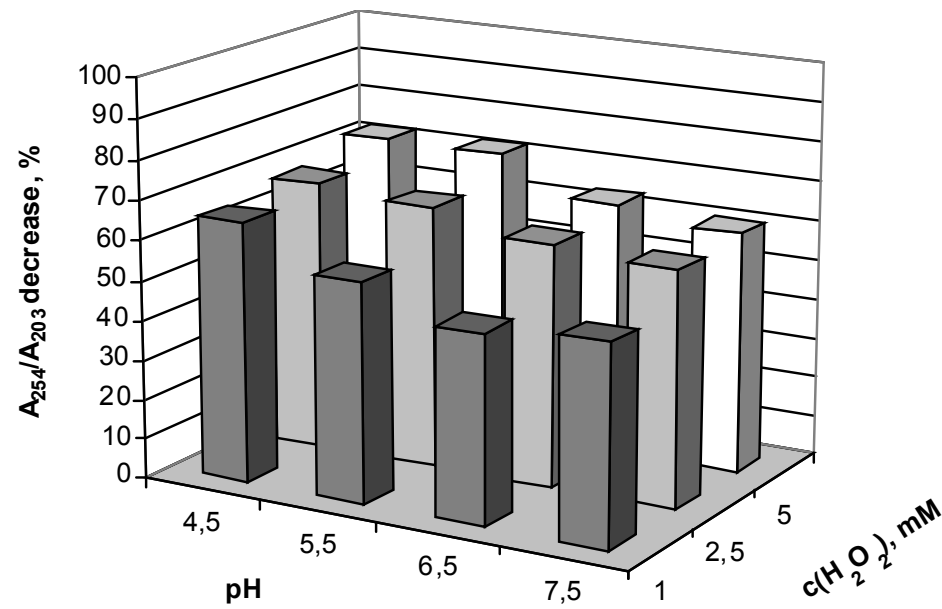

Figure 3. Effect of $\mathrm{H}_{2} \mathrm{O}_{2}$ dose on performance of Fenton's process for THMFP decrease (0.1 $\mathrm{mM} \mathrm{Fe}^{2+}, A_{254} / \mathrm{A}_{203} 0.4626,0.6 \mathrm{mg} \mathrm{L}^{-1}$ polyelectrolyte, 30 min mixing time)

\section{Effect of $\mathrm{Fe}^{2+}$ dose}

Fenton's process was conducted in triplicate with $\mathrm{Fe}^{2+}$ concentration of $0.1 \mathrm{mM}$, which was obtained by addition of $\mathrm{FeSO}_{4}$ solution in a raw water sample. The intention was to perform the process 
without further addition of $\mathrm{Fe}^{2+}$ ions, or in other words by using autochthonous iron from groundwater. The concentration level of $\mathrm{Fe}^{2+}$ in the raw groundwater from waterworks of town Osijek (Eastern Croatia) was $0.02 \mathrm{mM}$. Process efficiency was compared regarding these conditions. As expected, TOC removal at $0.02 \mathrm{mM}$ of $\mathrm{Fe}^{2+}$ was lower when compared with a system in which additional $\mathrm{Fe}^{2+}$ dose was added. At $0.02 \mathrm{mM} \mathrm{Fe}^{2+}$ concentration the removal of TOC was a maximum of about $20 \%$ and the removal was slightly $\mathrm{pH}$ dependent. At $\mathrm{Fe}^{2+}$ dose of $0.1 \mathrm{mM}, \mathrm{pH}$ dependence of the process was more expressed and maximum TOC removal (average $50 \%$ ) was achieved (Figure 4). The increase of iron concentration had a positive influence on the process, since iron has an important role in the Fenton's process. It is well known that Fenton's system has dual function of oxidation and coagulation for organic removal during water treatment. In the Fenton's process iron cycles between $\mathrm{Fe}^{2+}$ and $\mathrm{Fe}^{2+}$, and plays the role of catalyst. During the Fenton's process strong oxidative hydroxyl radicals are produced and the ferrous ions are oxidized to ferric ions. Since both ferrous and ferric ions are coagulants, the Fenton's process can therefore have the functions of coagulation in the treatment process - Fenton based ferric coagulation (Kang et al., 2002). Coagulation is happened due to the generation of insoluble agglomerates through the reaction of ionic iron species with opposite charged colloidal particles, and also due to the adsorption phenomena (Cheng and Chi, 2002). With the addition of excessive $\mathrm{H}_{2} \mathrm{O}_{2}$, most ferrous ions were quickly oxidized to ferric ions that had a strong hydrolyzing potential and were believed to have a high capacity for adsorbing organics and the significant removal of TOC was achieved due to adsorption by ferric hydroxides. At ambient $\mathrm{pH} \mathrm{Fe}^{2+}$ is hydrolyzed instantaneously and this approach is based on a single production of hydroxyl radicals (ljpelaar et al., 2002b) resulting in lower process efficiency at higher $\mathrm{pH}$ values. It is believed that at higher $\mathrm{pH}$ TOC is removed mainly by adsorption. Effect of $\mathrm{Fe}^{2+}$ dose on THMFP decrease was less visible and with the increase of $\mathrm{Fe}^{2+}$ concentration the efficiency of the process was slightly changed depending on a $\mathrm{pH}$ value from $50-60 \%$ at $\mathrm{Fe}^{2+}$ concentration of $0.02 \mathrm{mM}$ to $60-70 \%$ at $0.1 \mathrm{mM}$ (results not included).

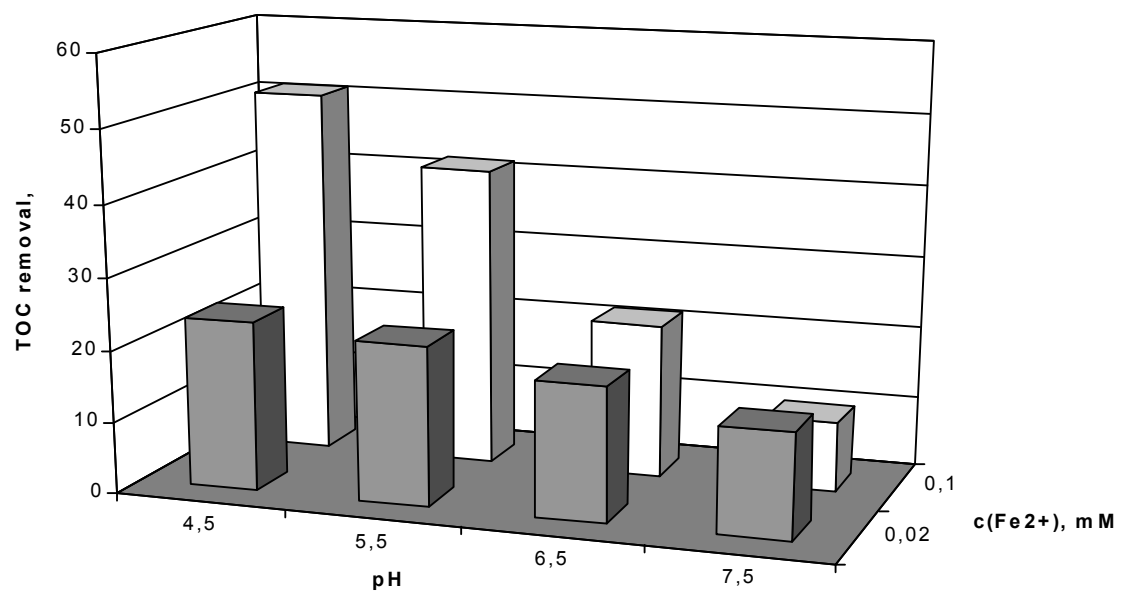

Figure 4. Effect of $\mathrm{Fe}^{2+}$ dose on performance of Fenton's process.

(2.5 $\mathrm{mM} \mathrm{H}_{2} \mathrm{O}_{2}, \mathrm{TOC}_{0} 5.45 \mathrm{mg} \mathrm{L}^{-1}, 0.6 \mathrm{mg} \mathrm{L}^{-1}$ polyelectrolyte, 30 min mixing time)

\section{Effect of polyelectrolyte/ activated carbon}

In an oxidation process of organic matter in water, lower molecular weight compounds are formed and then filtered and removed from water. In order to enhance filtration process, flocculant aid polyelectrolyte or activated carbon was added. Flocculants enhances gathering of organic byproducts, formed by oxidation, in floccules and their retaining on a filter. In the other case, byproducts from water are adsorbed on the surface of powdered activated carbon particles and retained on a filter together with activated carbon. Polyelectrolyte Accepta 4211 in concentration of $0.6 \mathrm{mg} \mathrm{L}^{-1}$ and activated carbon Norit SA Super in concentration of $25 \mathrm{mg} \mathrm{L}^{-1}$ were used. Comparison was made at $\mathrm{H}_{2} \mathrm{O}_{2}$ concentration of $2.5 \mathrm{mM}$ and $0.1 \mathrm{mM}$ of $\mathrm{Fe}^{2+}$. At lower pH values no significant difference in efficiency of these two additional materials in TOC removal was obtained and about $50 \%$ removal efficiency was achieved (Figure 5). The difference was more expressed at higher $\mathrm{pH}$ values when better results were obtained with activated carbon (about $30 \%$ of TOC was removed) than with polyelectrolyte (about $10 \%$ of TOC was removed). Generally, activated carbon 
was less affected with $\mathrm{pH}$ change and better results were obtained with activated carbon. Effect of these additional materials on THMFP was not visible and the removal efficiency was from $60 \%$ to 72 $\%$ depending on a $\mathrm{pH}$ value (results not included).

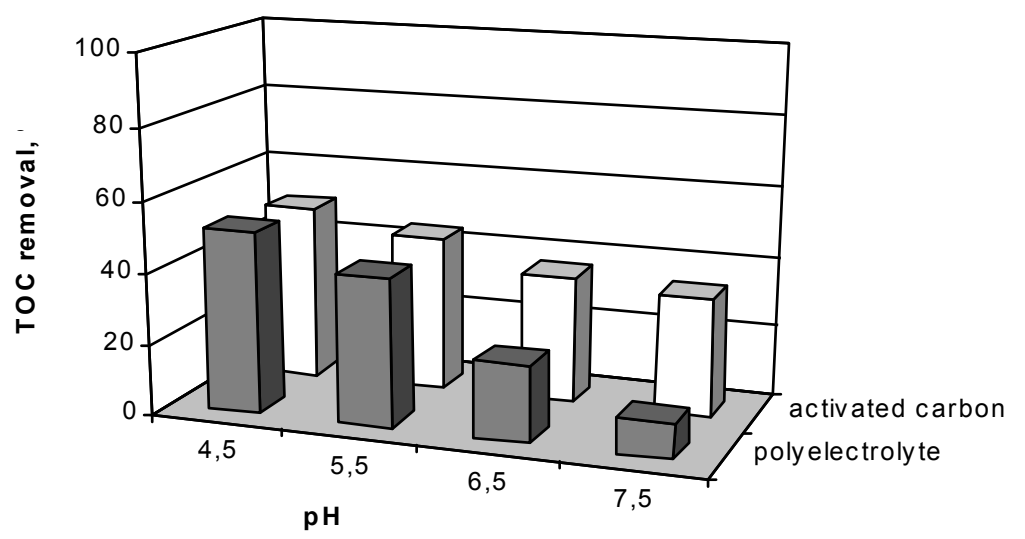

Figure 5. Effect of polyelectrolyte/ activated carbon dose on performance of Fenton's process (0.1 mM Fe ${ }^{2+}, 2.5 \mathrm{mM} \mathrm{H}_{2} \mathrm{O}_{2}, \mathrm{TOC}_{0} 5.45 \mathrm{mg} \mathrm{L}^{-1}, 0.6 \mathrm{mg} \mathrm{L}^{-1}$ polyelectrolyte, $25 \mathrm{mg} \mathrm{L}^{-1}$ activated carbon, 30 min mixing time)

\section{CONCLUSIONS}

1. Although Fenton's process is not a new process, nowadays it is getting more on importance when environmentally acceptable solutions in water treatment are needed. Fenton process fits completely to trends of decreasing or eliminating the harmful residues in the environment. Reagent components are environmentally benign and no amounts of residuum chemicals remain in water.

2. Fenton's process can be successfully used for NOM removal from groundwater. The key parameters of this process were $\mathrm{pH}, \mathrm{H}_{2} \mathrm{O}_{2}$ and $\mathrm{Fe}^{2+}$ dose. The effect of Fenton's process on TOC and THMFP decrease, estimated as ratio of absorbances at 254 and $203 \mathrm{~nm}\left(\mathrm{~A}_{254} / \mathrm{A}_{203}\right)$, was studied.

3. The process was more efficient at lower $\mathrm{pH}$ values, even though good removal efficiencies were achieved at natural $\mathrm{pH} 7.5$, especially regarding THMFP decrease. The removal of TOC was $\mathrm{H}_{2} \mathrm{O}_{2}$ dose dependant and at higher $\mathrm{pH}$ values it was increasing with increasing $\mathrm{H}_{2} \mathrm{O}_{2}$ concentration. At lower pH values maximum elimination of TOC at $2.5 \mathrm{mM} \mathrm{H}_{2} \mathrm{O}_{2}$ was observed. The increase of $\mathrm{Fe}^{2+}$ dose had a good influence on the process regarding TOC elimination, but this influence was less pronounced in THMFP decrease. When optimal conditions were used, the percentage of TOC removal was about $50 \%$ and the THMFP decrease reached $70 \%$.

4. Fenton process could be very useful in elimination of organic contaminants in real and close to real conditions. When Fenton's process was performed at natural $\mathrm{pH}$ of groundwater about 10 $\%$ of NOM could be removed. By slight decrease of $\mathrm{pH}$, performance of process increase considerably. When $\mathrm{pH}$ was estimated to $4.5,50 \%$ of TOC was removed from water and decrease of THMFP was observed of about $70 \%$.

5. Based on preliminary technical/economical evaluation implementation of Fenton's reagent in drinking water treatment process based on coagulation/flocculation wouldn't significantly decrease process costing, but obtain drinking water quantity would be improved.

6. Once optimized, Fenton's process could be applied to groundwater rich in organic contaminants as a new developing process for reducing organic matter levels. The results derived from the present study could provide useful information for practical purpose. Further work is required to make this method practical.

\section{REFERENCES}

Cohn P.D., Cox M. and Berger P.S. (1999), Health and Aesthetic Aspects of Water Quality. Water Quality and Treatment, R.D. Letterman (ed.), McGraw-Hill, Inc., New York

Cheng W.P. and Chi F.H. (2002), A Study of Coagulation Mechanisms of Polyferric Sulfate Reacting with Humic Acid Using a Fluorescence-Quenching Method, Water Res., 36, 4583-4591. 
Ferreira F., Carvalho L., Pereira R., Antunes S.C., Marques S.M., Gonçalves F., Duarte A.C., RochaSantos T.A.P., Freitas A.C. (2008), Biological and photo-Fenton treatment of olive oil mill wastewater, Global NEST Journal, 10, 419-425.

Greenberg A.E., Clesceri L.S. and Eaton A.D. (1999), Standard Methods for the Examination of Water and Wastwater. AWWA, Washington DC

Habuda-Stanić M., Kuleš M., Kalajdžić B. and Romić Ž. (2007), Quality of Groundwater in Eastern Croatia. The problem of arsenic pollution, Desalination, 210, 157-162.

ljpelaar G.F., Groenendijk M., Kruithof J.C. and Schippers J.C. (2002a), Fenton Process for the Combined Removal of Iron and Organic Micropollutants in Groundwater Treatment, Water Sci. Technol.: Water Supply, 2, 229-236.

ljpelaar G.F., Groenendijk M., Hopman R. and Kruithof J.C. (2002b), Advanced Oxidation Technologies for the Degradation of Pesticides in Ground Water and Surface Water. Water Sci. Technol.: Water Supply, 2, 129-138.

Kang S-F., Liao C-H. and Chen M-C. (2002), Pre-oxidation and Coagulation of Textile Wastewater by the Fenton Process, Chemosphere, 46, 923-928.

Kavitha V. and Palanivelu K. (2004), The Role of Ferrous Ion in Fenton and Photo-Fenton Processes for the Degradation of Phenol. Chemosphere, 55, 1235-1243.

Kleiser G. and Frimmel F.H. (2000), Removal of precursors for disinfection by-products (DBPs) differences between ozone- and OH-radical-induced oxidation, Sci. Total Environ., 256, 1-9.

Korshin G.V., Li C-W. and Benjamin M.M. (1997), Monitoring the Properties of Natural Organic Matter through UV Spectroscopy: A consistent theory, Water Res., 31, 1787-1795.

Murray C.A. and Parsons, S.A. (2004a), Advanced Oxidation Processes: Flowsheet Options for Bulk Natural Organic Matter Removal, Water Sci. Technol.: Water Supply, 4, 113-119.

Murray C.A. and Parsons S.A. (2004b), Removal of NOM from Drinking Water: Fenton's and PhotoFenton's Processes, Chemosphere, 54, 1017-1023.

Narodne novine - Official bulletin of the Republic of Croatia (2004), Book of Regulations on Health Safety of Drinking Water, No. 182/04.

Petruzzeli D., Boghetich,G., Petrella M., Dell'Erba A., L'Abbate A., Sanarica S., Miraglia M., (2007), Pretreatment of industrial landfill leachate by Fenton's oxidation, Global NEST Journal, 9, 51-56.

Singer P.C. (1999), Humic Substances as Precursors for Potentially Harmful Disinfection By-products, Water Sci. Technol., 40, 25-30.

Stasinakis A.S. (2008), Use of selected advanced oxidation processes (AOPs) for wastewater treatment a mini rewiev, Global NEST Journal, 10, 376-385.

Tang W.Z. and Tassos S. (1997), Oxidation Kinetics and Mechanisms of Trihalomethanes by Fenton's Reagent, Water Res., 31, 1117-1125.

Walling C. (1975), Fenton's Reagent Revisited. Acc. Chem. Res., 8, 125-131.

WHO (1993), Guidelines for Drinking Water Quality, Vol.1 Recommendations, Geneva. 